\title{
An analysis of outcomes in children with cystic fibrosis in a tertiary African centre: A retrospective study
}

\author{
R E M Mphahlele, MB ChB; V Naidoo, Cert Pulm (SA)(Paeds); S Thula, FCPaeds; R Masekela, PhD \\ Department of Maternal and Child Health, Nelson R Mandela School of Medicine, University of KwaZulu-Natal, Durban, South Africa
}

Corresponding author: RE M Mphahlele(mphahleler@ukzn.ac.za)

Background. Cystic fibrosis (CF) is a common genetic disorder in the white population that has become increasingly prevalent in populations of black African descent. Black African children with CF commonly present with nutritional and growth abnormalities. Objectives. To describe the characteristics of children followed up at the CF clinic at Inkosi Albert Luthuli Central Hospital, South Africa (SA). Methods. A retrospective chart review of clinical, laboratory and spirometric data of patients registered from January 2013 to January 2016. Results. Fifteen patients' data were reviewed. Their mean age was 132 months (range 26 - 219) and 53\% were male. Sixty percent of these children were white and $26.6 \%$ were black African. Collectively, the mean age at diagnosis was 45 months (range 0 - 156), although this was higher in non-whites: 104 months (range 48 - 156) v. whites 1.3 months (range 0 - 3). The white group had better nutritional status with body mass index (BMI) of $17.2 \mathrm{~kg} / \mathrm{m}^{2}$ compared with $14.5 \mathrm{~kg} / \mathrm{m}^{2}$ for non-whites. Age at diagnosis had a negative correlation with weight-for-age $z$-score $(-0.61, p<0.05)$ and body mass index (BMI) $(-0.54, p<0.05)$. The mean predicted forced expiratory volume in 1 second $(\mathrm{FEV}, \% \mathrm{p})$ was 70.0 (range $16.1-120.2)$. $\mathrm{FEV}_{1} \%$ p had a positive correlation with weight $z$-score $(0.83, p<0.001)$ and $\mathrm{BMI}(0.59, p<0.05)$. Five of the non-white patients had no mutations identified on the 30-mutation panel test.

Conclusion. CF is diagnosed late in non-white children in SA, affecting their growth and lung function. A genetic panel that includes mutations specific to children of African descent is required.

S Afr Respir J 2016;22(2):35-37. DOI:10.7196/SARJ.2016.v22i2.76

Cystic fibrosis (CF) is an autosomal recessive disorder common in white people, which has an increasing prevalence among people of African descent. In South Africa (SA), CF affects 1:2 000 white, 1:4 624 mixed-race and 1:12 000 black people. ${ }^{[1]}$ It is caused by mutations in the CF transmembrane conductance regulator gene located on chromosome 7q31. ${ }^{[2]}$ This results in impaired chloride transport across cell membranes causing characteristic respiratory and gastrointestinal symptoms. The typical clinical presentation is that of recurrent chest infection due to poor airway clearance of mucus, and failure to thrive because of pancreatic insufficiency. This phenotypic presentation has been shown to be different in the context of the SA population, of whom the majority are black African or of mixed-race descent. These populations commonly present with failure to thrive and protein energy malnutrition. ${ }^{[3]}$

Early diagnosis of CF prevents severe malnutrition and improves long-term growth ${ }^{[4]}$ In CF, nutrition and growth are determinants of lung health and, ultimately, survival. ${ }^{[5]}$ As a result of improved treatment in recent years, pulmonary function is reported to be better in children who are diagnosed with CF earlier in life. ${ }^{[6]}$ Data from various SA CF centres have shown improvements in lung function ${ }^{[7]}$ and nutritional status ${ }^{[8,9]}$ when compared with previous years, thought to be largely owing to earlier diagnosis, and improved treatment and diagnostic strategies.

Concerning the genetic diagnosis of $\mathrm{CF}$, the most common mutation is phelF508.del, which accounts for $81 \%$ of mutations in whites. ${ }^{[10]}$ It is less common in mixed-race populations, where it accounts for $53 \%$ of mutations, and is rarely found in black South Africans. The most common mutation in black South Africans is $3120+1 G>A$, with a carrier rate of $1: 90 .^{[1]}$ At least 1000 babies are expected to be born with CF in SA each year, but with a detection rate of only $46 \%$, most are missed by conventional genetic mutation testing panels. ${ }^{[3]}$ This not only reduces confirmation of CF in black patients but the use of genetic-based prognostic measures and treatment opportunities.

In the clinical course of CF, Pseudomonas aeruginosa colonisation has been reported to affect growth and lung function, with those colonised at a higher risk of deteriorating lung health. ${ }^{[1]} P$. aeruginosa status, mean predicted forced expiratory volume in 1 second $\left(\mathrm{FEV}_{1} \% \mathrm{p}\right)$, age and sex have all been shown to predict mortality in children with $\mathrm{CF}^{[11,12]}$

$\mathrm{CF}$ is not a condition confined to a single population. Understanding the differences and similarities in diagnosis, presentation and clinical course is a necessity in the southern African context. We therefore undertook a study to describe the clinical, laboratory and spirometric characteristics of a representative clinic population in KwaZulu-Natal (KZN) Province, SA.

\section{Methods}

Study population

A retrospective chart review of all patients attending the CF clinic at Inkosi Albert Luthuli Central Hospital, Durban between the period January 2013 and January 2016 was conducted. All patients attending the clinic during this period were included in the study.

\section{Clinical investigations}

Clinical data collected included age at diagnosis, current age, gender, weight, height, body mass index (BMI), race and $z$-scores for weight, height and BMI (calculations according to World 
Health Organization guidelines). ${ }^{[13]}$ Weight and height data were collected on the same day as lung function tests were performed. Age was calculated to the time at which data were collected in January 2016.

\section{Laboratory investigations}

Data collected included sweat test (Gibson and Cooke, with measurement of sweat chloride), genotype test (30-mutation panel test; Elucigene, UK) and sputum microbiology including colonisation status of the respiratory tract. Chronic colonisation was defined as the persistence of a pathogen on two or more sputum samples over a period of 6 months, as per Leeds criteria. ${ }^{[14]}$

\section{Spirometry}

Pulmonary function tests were conducted for all patients over the age of 6 years; this study reported on $\mathrm{FEV}_{1} \% \mathrm{p}$. The highest $\mathrm{FEV}_{1} \% \mathrm{p}$ value for the most recent year that the patient was seen during the study period was reported for each patient. Date of birth, gender and height, at the time of lung function test, were recorded for calculation of prediction values. Recorded spirometry test results were prebronchodilator values.

\section{Data analysis}

Data were recorded and stored using Excel, Microsoft Office Professional Plus 2013 (USA). Data were analysed using Stata 13.0 (StataCorp, USA). Means were calculated for age, weight, height, $\mathrm{BMI}$ and $\mathrm{FEV}_{1} \% \mathrm{p}$. Pearson correlation was used for comparing non-categorical variables, with $p<0.05$ considered significant.

\section{Ethical clearance}

Ethical approval to access patient records was obtained from the Biomedical Research Ethics Committee of the University of KZN (Ref. BCA469/15).

\section{Results}

Data were reviewed for a total of 15 patients, with mean age 132 months (range 26 - 219), $53 \%$ of whom were male. Forty percent of the children were non-white: $26.6 \%$ of black African descent, 6.7\% Indian and 6.7\% mixed race. Collectively, the mean age of diagnosis was 45 months (range 0 - 156) (Table 1).

On mutational analysis, five of the nonwhite patients had no mutations identified on the 30-mutation panel used for testing.
phelF508.del was the most commonly identified mutation in the clinic. Of the white population, four were heterozygote, four homozygote and one unknown. One non-white patient was heterozygote and of mixed-race descent (Table 1).

Age at diagnosis (Fig. 1) was higher in non-whites, at a mean age of 104 months (8.6 years) (range 48 - 156 months) compared with whites at a mean age of 1.3 (range 0 3) months. Age at diagnosis had a negative correlation with weight-for-age $z$-score $(-0.61, p<0.05)$ and BMI $(-0.54, p<0.05)$. The non-white group had poorer nutritional status than the white group, with mean BMI $14.5 \mathrm{~kg} / \mathrm{m}^{2}$ v. $17.2 \mathrm{~kg} / \mathrm{m}^{2}$, respectively. The mean $\mathrm{FEV}_{1} \% \mathrm{p}$ for the study population was 70.0 (range 16.1 - 120.2) (Table 2). $\mathrm{FEV}_{1} \% \mathrm{p}$ was positively correlated with weight $z$-score $(0.83, p<0.001)$ and BMI $(0.59, p<0.05)$.

Table 1. Demographics of children with CF

\begin{tabular}{ll}
\hline Variable & $\boldsymbol{n}(\%)$ \\
\hline Gender (male/female) & $8 / 7(53 / 47)$ \\
Mean age at diagnosis (months) & 45 \\
Ethnic group & \\
$\quad$ White & $9(60.0)$ \\
Black African & $4(26.6)$ \\
Indian & $1(6.7)$ \\
Mixed race & $1(6.7)$ \\
Mutations & \\
Heterozygous phelF508.del & $5(33.3)$ \\
Homozygous phelF508.del & $4(26.7)$ \\
Negative & $5(33.3)$ \\
Unknown & $1(6.7)$
\end{tabular}

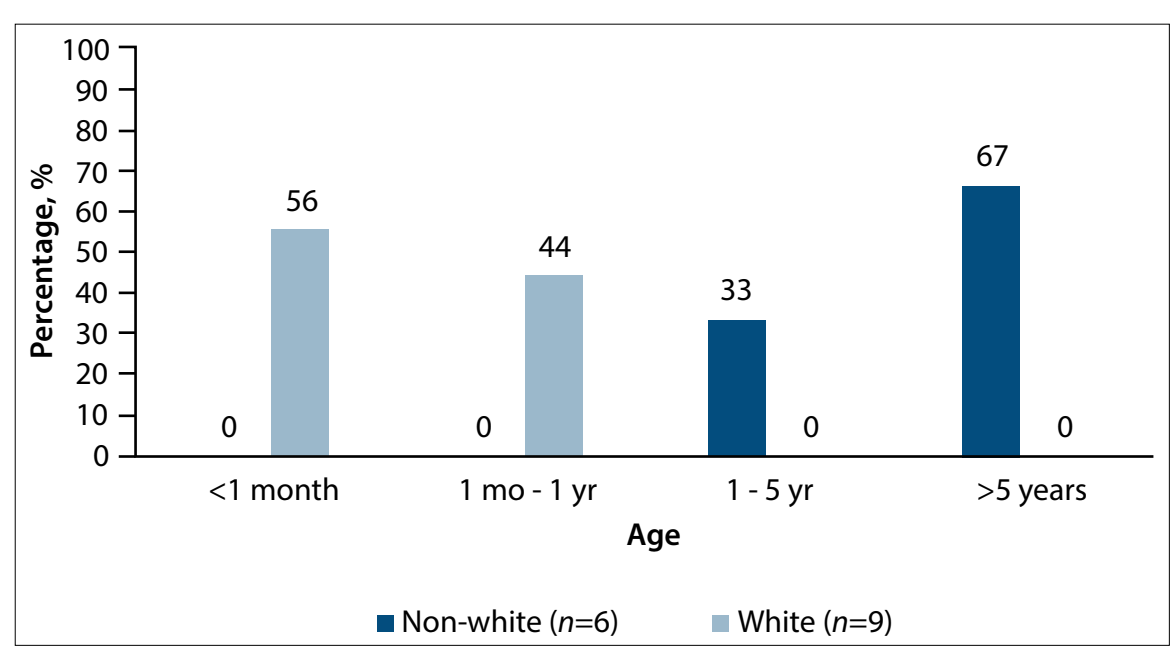

Fig. 1. Comparison of age at diagnosis in non-white v. white children.

Only three patients from the study population were chronically colonised with bacterial pathogens. One of these, with chronic Haemophilus influenzae colonisation, had a low $\mathrm{FEV}_{1} \% \mathrm{p}$ of 49.9 , BMI $16.6 \mathrm{~kg} / \mathrm{m}^{2}$ and intermittent Staphylococcus aureus growth on sputum. Chronic $P$. aeruginosa infection occurred only in two patients, both of whom were $>16$ years old. One of these patients was an 18-year-old male with a last recorded $\mathrm{FEV}_{1} \% \mathrm{p}$ of 31.0 and BMI $15.6 \mathrm{~kg} / \mathrm{m}^{2}$. His $\mathrm{FEV}_{1} \%$ p fell by $18 \%$ during the 7 -month lung function recording period before his death. The other patient was 16 years old, malnourished (BMI $14.7 \mathrm{~kg} / \mathrm{m}^{2}$ ) with $\mathrm{FEV}_{1} \% \mathrm{p}$ of $27.9 \%$, and previously colonised with S. aureus and Candida albicans.

\section{Discussion}

$\mathrm{CF}$ is a life-limiting condition that has encouraged a considerable amount of research, the bulk of which is undertaken in Western and developed countries, with developing countries such as SA following suit. The diverse populations within SA have presented a broader spectrum for the manifestation of $\mathrm{CF}$.

Table 2. Comparison of age at diagnosis, lung function and growth between white and non-white children

\begin{tabular}{lll}
\hline Variable & White & Non-white \\
\hline $\begin{array}{l}\text { Age at diagnosis } \\
\text { (months), mean }\end{array}$ & 1.3 & 104.0 \\
$\begin{array}{l}\text { Weight-for-age } \\
z \text {-score }\end{array}$ & -1.8 & -3.5 \\
FEV $_{1} \%$ p, mean & 77.9 & 56.1 \\
BMI $\left(\mathrm{kg} / \mathrm{m}^{2}\right)$, mean & 17.2 & 14.5 \\
Weight $z$-score & 1.7 & -3.6
\end{tabular}


Validating other studies, we show that there is a correlation between lung function, growth and age at CF diagnosis. ${ }^{[4-6]}$ We have also shown that for almost half of the population of our clinic, all of whom are black, recognition of CF is difficult, leading to late diagnosis and detrimental effects on disease progression. ${ }^{[15]}$ There may be many reasons for this, including a high prevalence of poverty-associated conditions with similar presentation, i.e. protein energy malnutrition, HIV infection and tuberculosis, which affect the black population in SA to a considerable extent. ${ }^{[3]}$ Another reason may be a high threshold for suspicion, as CF is not common in this population. One study in a Western country showed that features associated with late diagnosis were pancreatic insufficiency and certain genotypes. ${ }^{[16]}$

In addition, the definitive diagnosis of $\mathrm{CF}$ is difficult in this same population, with the current commercial 30-mutation panel proving too narrow for diagnosis. ${ }^{[17]}$ There is a great need for research in this field, as research into the treatment and prognosis of CF currently focuses on individual mutations in patients. ${ }^{[18,19]}$

Despite our small patient cohort, we were able to observe a trend in morbidity and mortality associated with increasing age and $P$. aeruginosa colonisation. ${ }^{[1]}$ The only patient who died in this study was severely undernourished, had $P$. aeruginosa colonisation and a yearly $\mathrm{FEV}_{1} \% \mathrm{p}$ decline of $18 \%$ - all clinical predictors of mortality. ${ }^{[11,20,21]}$

Some aspects of CF are similar across populations. ${ }^{[22]}$ However, knowledge about CF in the black population is limited. Despite the small numbers, this study highlights how this field requires dedicated research, with SA in an optimal position for this.

\section{Conclusion}

CF is diagnosed late in children of non-white origin in SA, and this negatively affects both their nutritional and pulmonary function outcomes. The current genetic panel misses a large number of mutations in the non-white population and, thus, research in this area is required.

Acknowledgements. We would like to acknowledge Mrs Ashleigh Robertson from the KZN CF association for her assistance with tracing a number of the patients.

\section{References}

1. Padoa C, Goldman A, Jenkins T, Ramsay M. Cystic fibrosis carrier frequencies in populations of African origin. J Med Genet 1999;36(1):41-44.

2. Riordan JR, Rommens JM, Kerem B, et al. Identification of the cystic fibrosis gene: Cloning and characterization of complementary DNA. Science 1989;245(4922):10661073. DOI:10.1126/science.2475911
3. Masekela R, Zampoli M, Westwood A, et al. Phenotypic expression of the $3120+1 G>A$ mutation in non-Caucasian children with cystic fibrosis in South Africa. J Cyst Fibros 2013;12(4):363-366. DOI:10.1016/j.jcf.2012.11.003

4. Farrell PM, Kosorok MR, Rock MJ, et al. Early diagnosis of cystic fibrosis through neonatal screening prevents severe malnutrition and improves long-term growth. Pediatrics 2001;107(1):1-13. DOI:10.1542/peds.107.1.1

5. Peterson ML, Jacobs DR, Milla CE. Longitudinal changes in growth parameters are correlated with changes in pulmonary function in children with cystic fibrosis. Pediatrics 2003;112(3):588-592. DOI:10.1542/peds.112.3.588

6. Wang SS, O'Leary LA, FitzSimmons SC, Khoury MJ. The impact of early cystic fibrosis diagnosis on pulmonary function in children. J Pediatr 2002;141(6):804-810. DOI:10.1067/mpd.2002.129845

7. Morrow BM, Argent AC, Zar HJ, Westwood AT. Improvements in lung function of a pediatric cystic fibrosis population in a developing country. J Pediatr (Rio J) 2008;84(5):403-409. DOI:10.2223/jped.1829

8. Westwood AT, Ireland JD. Children with cystic fibrosis in South Africa: An improving nutritional picture. J Trop Pediatr 2000;46(2):119-121. DOI:10.1093/tropej/46.2.119

9. Van der Spuy DA, Cader S, van der Spuy GD, Westwood AT. Improving nutritional status of children with cystic fibrosis at Red Cross War Memorial Children's Hospital. J Paediatr Child Health 2011;47(5):282-286. DOI:10.1111/j.1440-1754.2010.01954.x

10. Goldman A, Labrum R, Claustres M, et al. The molecular basis of cystic fibrosis in South Africa. Clin Genet 2001;59(1):37-41. DOI:10.1034/j.1399-0004.2001.590106.x

11. Emerson J, Rosenfeld M, McNamara S, Ramsey B, Gibson RL. Pseudomonas aeruginosa and other predictors of mortality and morbidity in young children with cystic fibrosis. Pediatr Pulmonol 2002;34(2):91-100. DOI:10.1002/ppul.10127

12. Kerem E, Reisman J, Corey M, Canny GJ, Levison H. Prediction of mortality in patients with cystic fibrosis. N Engl J Med 1992;326(18):1187-1191. DOI:10.1056/ nejm199204303261804

13. World Health Organization. WHO Child Growth Standards: Length/height-for-age, Weight-for-age, Weight-for-length, Weight-for-height and Body Mass Index-for-age: Methods and Development. Geneva: WHO, 2006.

14. Proesmans M, Balinska-Miskiewicz W, Dupont L, et al. Evaluating the 'Leeds criteria' for Pseudomonas aeruginosa infection in a cystic fibrosis centre. Eur Respir J 2006;27(5):937-943.

15. Sims EJ, Clark A, McCormick J, Mehta G, Connett G, Mehta A. Cystic fibrosis diagnosed after 2 months of age leads to worse outcomes and requires more therapy. Pediatrics 2007;119(1):19-28. DOI:10.1542/peds.2006-1498

16. McCloskey M, Redmond A, Hill A, Elborn J. Clinical features associated with a delayed diagnosis of cystic fibrosis. Respiration 2000;67(4):402-407. DOI:10.1159/000029538

17. Goldman A, Graf C, Ramsay M, Leisegang F, Westwood A. Molecular diagnosis of cystic fibrosis in the South African population. S Afr Med J 2003;93(7):518.

18. Ramsey BW, Davies J, McElvaney NG, et al. A CFTR potentiator in patients with cystic fibrosis and the G551D mutation. N Engl J Med 2011;365(18):1663-1672. DOI:10.1056/nejmoa1105185

19. Ratjen FA. Cystic fibrosis: Pathogenesis and future treatment strategies. Respir Care 2009;54(5):595-605. DOI:10.4187/aarc0427

20. Sharma R, Florea V, Bolger A, et al. Wasting as an independent predictor of mortality in patients with cystic fibrosis. Thorax 2001;56(10):746-750. DOI:10.1136/ thorax.56.10.746

21. Milla CE, Warwick WJ. Risk of death in cystic fibrosis patients with severely compromised lung function. Chest 1998;113(5):1230-1234. DOI:10.1378/chest.113.5.1230

22. Hamosh A, FitzSimmons SC, Macek Jr M, Knowles MR, Rosenstein BJ, Cutting GR. Comparison of the clinical manifestations of cystic fibrosis in black and white patients. J Pediatr1998;132(2):255-259. DOI:10.1016/s0022-3476(98)70441-x 